\title{
Geleentheidsrede
}

\section{Problemen en crisis van de opgezweepte Westerse technologische cultuur}

\author{
E. Schuurman \\ Bijzonder hoogleraar in de Reformatorische Wijsbegeerte \\ Technische Universiteiten van Eindhoven en Delft en \\ Landbouwuniversiteit van Wageningen \\ NEDERLAND
}

\begin{abstract}
Western culture is in its kernel a technological culture. This culture is speeded up by technology and is characterized by a lot of problems, such as pollution and labour problems, the growing distance between developed and underdeveloped countries and the one-sidedness in the normative orientation. This culture is in a crisis because there is no agreement about the cause of and the way o solve the problems.

At the bottom of the spirinal-historical background of Western culture the 'hidden' ideology of technology is active. The contents of this ideology implies that man pretends to be an autonomous master of reality, that he can therefore manipulate everylhing, that he can solve all old and new problems by scientific-technological control, and that he can guarantee the progress of material welfare. Ideology as a driving force ensures a 'technological paradise', in which the perspective of eternity has been lost. The ideology of rechnology is strengthened by the ideology of science and economy. Together they are the cause of cultural problems.

To overcone the problems and the crisis of technological culture a spiritual reorientation is necessary. In the light of Holy Scripture it ought to be acknowledged that everything created is marked by the consequences of sin, redeemed through Jesus Christ in communion with the Holy Spirit, and waiting for the recreation. In the 'meantime' man's mind ought not to be autonomously technical, but a mind directed at obeying God's Law and the coherence norms: that is the direction of the Kingdom of God. The consequence of this viewpoint is that in the field of technology, economics and science man ought to obey the commandment of love as a concentration of all normativily. liurthermore man should choose the perspective of righreousness and justice as norm. By accepting love as a focal point and
\end{abstract}


Problemen en crisis van de opgezweepte Westerse technologische cullumr

righteousness as coherence of normativity, technology assumes a serviceable function, and the culture becomes more stable and healthy. Not all problems, however, will be solved, but they will become bearable in the perspective of the eternity of the Kingdom of God: problems will wait for the recreation of everything by God.

\section{Inleiding}

In dit artikel gaat het over de Westerse cultuur, waarop de technologie zo 'n uitzonderlijk stempel heeft gezet. Die cultuur wordt daarom ook wel de technologische cultuur genoemd, dat wil zeggen dat in die cultuur alles door de bril van de technologie wordt gezien en dat alles tot object wordt van de wetenschappelijktechnische beheersing. Aanvankelijk werd die cultuur met optimisme begroet. $\mathrm{Nu}$ we er midden inzitten, zijn de problemen groot. In een recent rapport van de Club van Rome (Meadows et al., 1992) worden die problemen genoemd: de energiebronnen raken op, zure regen, gaten in de ozonlaag, broeikaseffect en klimaatveranderingen bergen naast vele bekende gevolgen ook grote onzekerheden in zich. De tegenstellingen tussen rijke en arme landen nemen toe. Naast het milieuprobleem en de groeiende annoede van de Derde Wereld wordt de technologische cultuur intern geteisterd door grote arbeidsproblemen. Velen zijn niet in staat via arbeid aan die cultuur deel te nemen of worden vroegtijdig vanwege fysieke of psychische druk uitgeschakeld.

Geconfronteerd met de ernst van de cultuurproblemen en met het besef dat we in een cultuurcrisis verkeren - er is namelijk geen eensgezindheid over ontstaan en oplossing van de problemen - is diepgaande bezinning noodzakelijk. Pas dan kan er sprake zijn van heroriëntatie. Het zal blijken dat de jacht op de toekomst moet worden gestaakt en dat authentieke normen en waarden moeten worden herontdekt. De vraag die ons bezig houdt is: Zou de verengde, hyper-technologische cultuur omgezet kunnen worden in een verbrede, veelzijdige cultuur? Zou in plaats van een kwantitatieve groei niet veel meer aandacht moeten komen voor een kwalitatieve groei? Zou een hoger niveau van wonen, voeding, gezondheid, kleding en onderwijs ook kunnen samengaan met toenemende rust en vrije tijd, in de zin van creatieve tijd, in plaats van onrust en onzinnig tijdverdrijf. Indien dat zou kunnen, moeten dan duurzaamheid, stabiliteit en consolidatie geen 'trefwoorden' worden in een ontspoorde, moeilijk nog te beheersen technologische cultuur?

Om diepte van de cultuurproblemen en van de cultuurcrisis te kunnen peilen is het noodzakelijk dat allereerst aandacht gegeven wordt aan de geestelijk-historische achtergrond van de cultuur. Daanna moet de verborgen ideologie van de technologie als drijfkracht in de cultuur worden ontmaskerd. Een kritische bezinning op de cultuuropdracht vormt de voorwaarde voor het wijzen van een zinvol cultuurperspectief en voor een juiste heroriëntatie in de cultuur 


\section{Geestelijk-historische achtergrond}

De geestelijk-historische achtergrond van de technologische cultuur komt vooral tot ontwikkeling als na de Middeleeuwen de mens steeds meer op zichzelf als laatste steunpunt in de werkelijkheid wijst - het antropocentrisme - en de mens vanuit die positie claimt 'Heer en Meester' over de werkelijkheid te zijn.

Vanuit de geestesgeschiedenis van het Westen is te verdedigen dat de actuele dominante cultuurstroom een uiting is van de Renaissance, van de moderne filosofie en van de Verlichting. Het zijn de motieven van deze geestesbewegingen die zich in onze cultuur via de filosofie en wetenschap in de technologie sterk maken en zich nog steeds verbreden. Daarom is onze cultuur mét dat zij een technische cultuur is, ook tegelijk een door en door geseculariseerde, godloze cultuur.

Daarmee heb ik een punt aangesneden dat niet door velen wordt verdedigd, maar dat, zo heeft de ervaring mij geleerd, ook natwelijks bestrijding ondervindt. Wanneer men eenmaal vanuit de geestelijk-historische achtergrond van onze cultuur de geestelijke samenhang tussen onze technische cultuur en de secularisatie de godloosheid - heeft onderkend, breekt een diep stilzwijgen aan. Men weet er kennelijk geen raad inee. Er schijnt geen ontkomen aan te zijn. Maar zouden we dan niet moeten constateren inisschien wel met een moderne, afgodische macht te maken te hebben, waartegen het uitermate moeilijk strijden is?

De Westerse cultuur is een door en door antropocentrische cultuur geworden: de mens met zijn macht staat in het middelpunt. De macht van de wetenschappelijktechnische beheersing, die alle cultuursectoren doortrekt en stempelt, dat is een macht waaraan de mens zelf ondergeschikt schijnt te raken en waardoor de natuur wordt uitgebuit.

Vanzelfsprekend onderkemnen velen het probleem van het antropocentrisme van onze cultuur. Tegelijk weigert men echter de weg terug te gaan naar het theocentrisme en meer dan eens kiest men voor het ecocentrisme - en daaruit blijkt dat men gevangen zit in de dialectiek van cultuur en natuur, of te wel de dialectische spanning tussen het antropocentrisine van onze wetenschappelijk-technische cultuur en het ecocentrisme van cultuuralternatieven (Corbey \& van der Grijn, 1990). Die dialectiek demonstreert het neo-pagane van onze geseculariseerde cultuur. De vòòr-christelijke motieven, ontleend aan natuurgoden en cultuurgoden (Dooyeweerd, 1949), hebben in het neo-pagane tijdperk de vorm aangenomen van enerzijds de verering van de wetenschappelijk-technische beheersingsmacht - de welvaartsgod - en anderzijds de verering van de natuur - 'moeder aarde' - in allerlei variaties van 'tegen-cultuur' en het New Age-denken. 
Wanneer christenen voor deze hoofdkarakteristiek van de cultuur geen aandacht hebben, moet gevreesd worden dat zij erdoor worden beheerst. Het gevolg is dat men zich in het verzet tegen de verafgoding van de cultuur vervolgens nogal eens gemakkelijk gevangen laat nemen door het naturalisme, of omgekeerd. Het inzicht zou veld moeten wimnen dat deze dialectiek ontstaat omdat men Gods openbaring over de werkelijkheid miskent. Men erkent de werkelijkheid niet langer als schepping van God, laat staan dat men de diepte van de zondeval en daarmee ook de totale en radicale verlossing door Christus en de verwachting van de herschepping belijdt. De geschetste dialectiek parasiteert ondertussen op Gods schepping en op Christus verlossingsmacht en ontleent daaraan haar kracht. Maar zonder erkenning van God en Christus wordt die kracht een cultuur- en natuurverwoestende kracht.

In paragraaf 5 zal ik straks proberen duidelijk te maken, dat wij voor een bevrijdend perspectief van onze cultuur ons op Gods schepping en op Christus verlossingsmacht dienen te oriënteren. Maar eerst moet ik de tot nu toe geuite kritiek nog verdiepen en verbreden.

\section{Het scharnierpunt: de ideologie van de technologie}

Over het algemeen wordt - ook door christenen - de technische ontwikkeling in onze cultuur bijna kritiekloos geaccepteerd. Dat was ook al zo bij Kuyper in 1891. Alhoewel hij in zijn architectonische maatschappijkritiek duidelijk uitgaat van het eeuwigheidsperspectief in de cultuur, spreekt hij nauwelijks relativerend over de techniek. Dat lag ook wel enigszins voor de hand. De moderne techniek was in opkomst. En wie zou willen ontkennen dat zij veel beloften inhield met betrekking tot het opheffen van armoede, honger, en ziekte? En dat zij bovendien de mogelijkheid zou bieden voor een geestelijk rijkere cultuur? En zijn dat niet allemaal tekenen van het Rijk Gods? Terecht heeft Kuyper ingezien dat we de techniek nodig hebben. Maar veel te weinig heeft hij het gevaar van de ideologisering ervan onderkend. Misschien was Kuyper er al wel zelf het slachtoffer van toen hij in zijn Pro Rege de techniek zelfs als een groter wonder beschouwde dan de wonderen van Jezus (Kuyper, 1911:143 e.v.).

De vergissing van Kuyper - als kind van zijn tijd - was dat hij geen aandacht had voor de (mogelijke) dreigingen van de moderne techniek. Kuyper vergat de bijbelse waarschuwing, dat de mens met de techniek God naar de kroon kan steken, zich op aarde een naam wil vestigen, en zo een cultuur-los-van-God (een Babelcultuur) wil bouwen. Juist de alleen maar lovende beoordeling van de techniek door Kuyper heeft nazaten van hem verblind. Het zal nogal wat tijd kosten voordat de moderne techniek echt kritisch wordt geanalyseerd. Alhoewel de lof op de techniek vandaag niet meer vlekkeloos is, gaat de kritiek er op niet erg diep. Vanuit het eeuwigheidsperpectief die kritiek uiten, is bittere noodzaak. 
Dit is ook uiternate actueel: bij de herdenking van het Eerste Christelijk Sociaal Congres in 1991 kwamen wel de problemen rond de beheersbaarheid van de technische ontwikkeling aan de orde, maar de achtergronden van de moderne technische ontwikkeling en haar problemen bleven onbesproken. En juist die achtergronden moeten voor een goede heroriëntatie binnen de cultuur in zicht komen.

De techniek is de basis voor alle cultuuractiviteiten en de technische ontwikkeling is tegelijk de motor ervan. Als er met die techniek iets mis is, gaat het met heel de cultuur mis. Beter gezegd: wanneer de techniek onder invloed staat van verkeerde motieven - bijvoorbeeld dat de mens heer en meester is over de werkelijkheid, of dat alles wat gemaakt kan worden, ook moet worden gemaakt - , en dus het technologisch imperatief als norn wordt aanvaard, vormt dat de grondoorzaak van vele problemen in de cultuur.

Meestal gaat men in de maatschappijkritiek uit van de techniek als iets neutraals, dat pas gevaarlijk kan worden binnen een verkeerde economisch-maatschappelijke orde. En wanneer men let op de problemen van de Derde Wereld kan een kritiek op de ideologie van de markteconomie daarop een beter zicht geven. Ook arbeidsproblemen en milieuvervuiling en natuurverwoesting in onze cultuur zijn er door te begrijpen. Toch zou er een nog beter zicht op die problemen ontstaan, indien de kritiek op de ideologie van de markteconomie zich zou verdiepen in de richting op de ideologie van de technologie. Maar daarvoor schijnt men een blinde vlek te hebben.

Bij velen ontbreekt het inzicht dat de ideologie van de technologie - door mij ook wel de geest van het technicisme genoemd - vooraf gaat aan de ideologie van de markteconomie (Schuurman, 1985:9-30 en 1989:11-23). Dezelfde benadering zou ook gegeven kumnen worden door over het technische wereldbeeld te spreken (Strijbos, 1988).

Dat de cultuurkritiek moet aanvangen bij de ideologie van de technologie is niet gangbaar, maar wel noodzakelijk. Daarvoor zijn vele redenen te noemen. In de eerste plaats maakt een kritiek op de ideologie van de economie - het economisme - niet duidelijk dat de ontwikkeling van veel technologieën vele economische offers heeft gevraagd, zoals bijvoorbeeld oorlogstechnologie in het algemeen, en de kernwapentechnologie in het bijzonder. Maar ook in de ontwikkeling vall de ruimtevaarttechnologie werden vele economische offers gevraagd; daarin ging het niet om het economisch gewin, maar om de naam en de eer van de toenmalige grootmachten! Ook is de werkzaamheid van het technische wereldbeeld breder en dieper dan die van het economisme. Vele wetenschappen, zoals het recht, de psychologie en zelfs de theologie drukken zich uit in technische categorieën. Het economisme is daarvoor veel minder passend. 
Maar hoe is het dan toch mogelijk dat de ideologie van de technologie in christelijke kring zo weinig aandacht krijgt? Zou dat kunnen komen ondat de marktideologie wel verdedigers heeft - denk aan Adam Smith - , maar de ideologie van de technologie niet? Als een verborgen ideologie is zij niet minder werkzaam. Komt de geringe aandacht daarvoor misschien omdat de techniek sinds de zondeval een verleidende macht is. De ideologie van de zelfverlossing is in eerste instantie de ideologie van de techniek en in moderne vorm die vall de moderne, met wetenschap doorspekte technologie. Wel moet worden ingezien dat de ideologie van de techniek in de geseculariseerde cultuur nieuwe kansen $\mathrm{kreeg}$, toen zij werd versterkt door de ideologie van wetenschap en economie.

Kortom, de autonomie of eigenmachtigheid van de Westerse mens hecht zich het eerst aan de moderne techniek en zet van daaruit een stempel op heel de cultuur. De 'technische geest' was er eerder dan de moderne wetenschap en economie; vandaar dat die wetenschap en economie ook van meet af aan door de technische beheersingsdrift werden gestempeld. Het technische wereldbeeld is met andere woorden ouder dan de natunrwetenschap en de moderne economie, alhoewel die wetenschap en economie op hum beurt als in een spiraal - via een positieve feedback - de technische ontwikkeling opvoeren.

Deze geseculariseerde visie ontmoeten we reeds in utopieën die aan de mogelijkheden van de techniek zijn ontleend. Te denken valt aan utopieën van Roger en Francis Bacon (Nova Atlantis!) uit respectievelijk de 13de en de 16de eeuw (Ihde, 1985). Francis Bacon verwachtte met de teclmiek - en daaruit blijkt de overschatting van de techniek - de gevolgen van de zondeval te boven te kunnen komen.

Zoals gezegd, slechts weinigen hebben oog voor de diepe wortels van de ideologie van de techniek, of het technische wereldbeeld. Dat geldt niet voor de Franse cultuurfilosoof Jacques Ellul en de Amerikaanse theoloog Paul Tillich. Zij hebben in hun kritiek op de 'technische maatschappij' aandacht gevraagd voor de geest van de technische ontwikkeling. Daarin ligt een verdieping en een verbreding van de visie op de huidige cultuur. Zij laten zien hoezeer bijvoorbeeld het onderwijs, het recht, de ethiek en zelfs de religie door een verabsoluteerde technische houding - wat zij dan meer dan eens het instrumentalisme noemen dreigen gestempeld te worden. $\mathrm{Zij}$ maken bovendien duidelijk dat een overspannen technische gezindheid de oorzaak is van veel sociale en economische misère (Ellul, 1980 en Tillich, 1986)

Om elk misverstand uit te sluiten: mijn kritiek betreft niet de technologie als zodanig, maar de ideologie van de technologie. Deze ideologie heeft door de invloed van de wetenschap op de techniek het karakter gekregen van de ideologie van de wetenschappelijk-teclunische beheersing. Met die wetenschappelijk-tech- 
nische beheersing wil men eigenmachtig heel de werkelijkheid naar de hand van de mens zetten, wil men alle voorkomende problemen oplossen en de groei van de materiële welvaart garanđeren om op die wijze de volmaaktheid te kunnen realiseren. De mens-zonder-God probeert met zijn wetenschappelijk-technische beheersingsmacht heer en meester over heel de werkelijkheid te zijn. Hij wil op die wijze een aards paradijs realiseren; het eeuwigheidsperspectief is verdwenen; de hemel is door het technische wereldbeeld gesloten. Door de breuk tussen de goddelijke wereld en de aardse werkelijkheid heeft de mens zijn hart op de techniek en haar resultaten gezet. Deze technicistische geest is de religieuze drijfkracht in onze technische maatschappij en zij wordt door de welvaartspolitiek enorm versterkt.

De resultaten van deze ontwikkeling bleven niet uit. Vooral na de Tweede Wereldoorlog gingen velen buiten wetenschap en techniek de onbegrensde technische ontwikkeling vereren vanwege de materiële successen. Materialisme en consumentisme zijn daarvan de gevolgen. Nooit is er daarom een tijd als de onze geweest die zo technisch is, maar ook nooit is er een tijd geweest die geestelijk zo leeg is. Overbodigheid, rusteloosheid, onbegrensdheid en 'tijd doden' zijn uitingen van het culturele verschralingsproces en van de geestelijke doodsheid. Dat is het gevolg van de pretentie van de mens, die zijn technische macht tot zijn god maakt. Dat is ook ten diepste de achtergrond van geloofsafval, van kerkverlating, van secularisatie en 'godsverduistering'. Als de goddeloze verslindt, zwijgt God, zegt Habakuk (1:13).

Momenteel beheerst de ideologie van de technologie het centrum van de cultuur. Zij legt een bijna absolute claim op onze maatschappij. Door deze ontwikkeling zijn vele cultuursectoren door de wetenschappelijk-technische beheersing gestempeld. Niet alleen de industrie, maar ook de landbouw, de gezondheidszorg, het maatschappelijk werk, het onderwijs, enz. worden erdoor beheerst. Men tracht zelfs de problemen die dat met zich meebrengt, met de moderne techniek weer op te lossen. Let er eens op hoe bijvoorbeeld de informatietechnologie, de biotechnologie en de genetische manipulatie als vanzelfsprekende oplossingen worden aangedragen voor milieuproblemen, voor arbeidsproblemen, enz. Maar zelden wordt de vraag gesteld of we daarmee wel op de goede weg zijn. Integendeel, we verdoezelen op deze manier de problemen - in elk geval voor een tijd, om er straks in verhevigde mate opnieuw mee geconfronteerd te worden. Vanuit dit gezichtspunt zou ook ingezien moeten worden dat de problemen van de werkloosheid, van de arbeidsongeschiktheid, van de milieuvervuiling, van arbeid als slechts produktieve arbeid, - met veronachtzaming van transductieve, creatieve en zorgende arbeid - niet incidenteel, maar structureel zijn. Bovendien zal als gevolg van de ideologie van de technologie de groei in materiële welvaart individualisering kansen geven en de daarmee verwante problemen oproepen, zoals verlies aan gemeenschapszin en maatschappij-ontbinding. Ook de tendens naar 
éénzijdige, materialistische, grootschalige politieke kaders valt uit die ideologie van de technologie te verstaan. Internationale politiek staat vaak onder invloed van het technisch imperialisme.

\subsection{Technische perfektie en dwangmatigheid}

Ter toelichting het volgende: Onder invloed van de ideologie van de technologie zijn de hoofdnormen in de technische ontwikkeling de technische perfektie en het technische imperatief; wat gemaakt kan worden, moet ook worden gemaakt! Onze cultuur is daardoor in een dynamiek terecht gekomen, die ons naar een technisch paradijs zou moeten leiden, maar in werkelijkheid ons confronteert met een desastreuze ontwikkeling. De techniek is geperverteerd; daarom spreken we wel van de Januskop van de moderne techniek. Imnners de dwangmatige en eenzijdige dynamiek van de techniek veroorzaakt toenemende milieuvervuiling en natuurverwoesting, uitstoting van werknemers, die technisch gezien overbodig worden. In de verhoging van arbeidsproduktiviteit op basis van de ontwikkeling van nieuwe technieken, schuilt het menselijk probleem dat velen fysiek of psychisch niet aan de gestelde voorwaarden kunnen voldoen en daarom wel ziek moeten worden verklaard. Een hoog-technologische maatschappij vraagt kwalitatief hooggeschoolde werknemers, die zich dan bovendien vanwege de voortgaande technologische vernieuwingen en sterk wijzigende organisaties voortdurend moeten herscholen en aanpassen. Laaggeschoolden blijven werkloos, terwijl hooggeschoolden dat in de loop van hun leven wórden, indien ze gaan achterlopen bij de technologische en organisatorische vernieuwingen.

En niet te vergeten: deze ontwikkeling vergroot de armoede en honger in de Derde Wereld, omdat onze technische vooruitgang en economische groei elke rechtvaardige verdeling missen. En als ook de Tweede en Derde Wereld opgetild worden naar hetzelfde slopende welvaartsniveau van het Westen - en wie zou hen het recht daartoe willen ontzeggen? - , zullen op korte termijn de problemen van de technologische cultuur op wereldniveau dramatische vormen gaan aannemen. De uitkomst zal zijn dat deze ontwikkeling ten koste gaat van de natuur, van de verre naaste en de toekomstige generaties. De toekomst van de aarde is in het geding.

\subsection{Andere richting voor en orde van de techniek}

We zullen dus veel kritischer naar de motieven van de technische ontwikkeling en naar de orde en struktuur van de techniek moeten kijken.

De architectonische maatschappijkritiek moet beginnen zich te richten op de 'technische maatschappij'. Door een onkritische verbinding van wetenschap en techniek worden we met een logisch-noodzakelijke ontwikkeling van de techniek 
geconfronteerd. De modene techniek is daarom dwangmatig, grootschalig, massaal, universeel, reducerend en nivellerend, dus ééndimensionaal en onpersoonlijk. De mens gaat meer aan de hand van die techniek, dan dat de mens de techniek in de hand heeft. De invloed, die van deze techniek op de mens en zijn cultuur uitgaat, leidt tot ontmenselijking en vervreemding, tot een zakelijke, kille en innerlijk verscheurde cultuur. Van de wetenschappelijk-technische beheersing gaat een concentrerende en grootschalige invloed uit op de wetenschap, de economie, de politiek enz. Het actuele streven naar één Europa maakt dat duidelijk. Soms wordt zelfs gesuggereerd dat de 'onstuitbare kracht van de technologie' deze eenheid noodzakelijk maakt.

In dit verband zou ik er op willen wijzen dat de trend van een technologisch en economisch sterk Europa de maatschappelijke problemen eerder zal doen toenemen dan afinemen. Het aantal economische vluchtelingen zal toenemen; spanningen met minderheden, die nu soms al gevaarlijke proporties aannemen, zullen groeien. Wanneer daarenboven wordt ingezien, dat indien de eenzijdige ontwikkeling van Europa - het technologisch Europa - zich doorzet, de ontwikkelingslanden daarvan eerder de dupe zullen worden, dan er voordeel bij zullen hebben, vormt dat opnieuw een reden fundamentele kritiek op de bestaande politieke trend te hebben. Wamneer Europa onder het juk van de 'onstuitbare kracht van de technologie' door moet, moeten we vrezen dat het milieuprobleem, het arbeidsprobleem en de problematiek van de Derde Wereld groter worden. Een technologisch Europa zal een toenemende ramp voor het milieu zijn.

Arbeidsproblemen zoals we die nu al kennen, zullen een nog sterker structureel karakter krijgen. Tot nu toe is deze dimensie in het debat over Europa nauwelijks of niet aan de orde geweest, omdat men geen aandacht geeft aan de ideologie van de technologie.

Om opnieuw elk misverstand uit te sluiten: wanneer men werkelijk in een Verenigd Europa de genoemde problemen zou willen oplossen, dan zou daartoe veeleer een aanzet gegeven moeten worden door meer aandacht te vragen voor het dienen en bevorderen van publieke gerechtigheid in zo 'n Europa. Dan zou men in dat Europa de jacht op de toekomst staken, de juiste prioriteiten in politieke zin weer durven stellen en daarbij vooral aandacht geven aan de norm van de sociale rechtvaardigheid in de verdeling van materiële goederen. De bestaande hoofdtrend zal overigens niet gemakkelijk te keren zijn. Naar mijn overtuiging is verzet tegen de feitelijke grootschalige politieke constructies dan ook blijvend geboden! 


\section{Cultuuropdracht}

Om tot een echte heroriëntatie te komen is het nodig aandacht te vragen voor een hernieuwde bezinning op de cultuuropdracht. Ook al spreken wij over cultuuropdracht tot eer van God en wijzen we een welvaartseconomie af - wat gelukkig in christelijke kring veel voorkomt -, als we een kritische bezinning op de techniek nalaten, dan lopen we misschien toch in de val van de geseculariseerde ideeën van de Verlichting. Het zou bovendien funest zijn te denken dat die geseculariseerde ideeën zouden kunnen worden gechristianiseerd. We zullen terug moeten naar het authentieke bijbelse denken over cultuurontwikkeling.

Het valt niet te ontkennen dat het spreken over cultuuropdracht in christelijke kring vaak onkritisch gebeurt en met voorbijzien aan de ideologie van de techniek. Een meer bijbelse bezinning is nodig. Inderdaad leert Genesis ons de cultuuropdracht. Maar de Bijbel laat er op vele plaatsen geen misverstand over bestaan dat juist de technische ontwikkeling de mens van God kan afvoeren. Dat leert de Bijbel over Kain, het geslacht van Lamech, de torenbouw van Babel, Nebukadnezar, en in het laatste Bijbelboek is de profetie over de opkomst van Babel daarvan een overduidelijk voorbeeld. Dit bijbels licht is ook de toets voor de juiste waardering van wat ik tot nu toe gezegd heb over de ideologie van de technologie.

Om de bestaande eenzijdigheid in het verstaan van de cultuuropdracht te voorkomen, zouden we die opdracht wat meer moeten zien in het licht van meerdere bijbelgedeelten, zoals bijvoorbeeld het gebed van Koning Salomo om wijsheid ( 1 Kon. 3) en het leven uit die wijsheid:

Hij sprak over de bomen, van de ceder van de Libanon af tot de hysop toe, die uit de muur uitschiet; hij sprak ook over het vee, het gevogelte, het kruipend gedierte en de vissen (1 Kon. 4:33-34).

Ook Psalm 148 geeft een andere toonzetting dan het spreken over cultuuropdracht verbonden met alleen het technische denken: "Hemel en aarde, looft den HEERE". En verder: van Abraham, de vader van alle gelovigen, - en zouden de gelovigen van de twintigste eeuw hem niet moeten volgen? - wordt gezegd dat zijn cultuurhouding bepaald wordt door het pelgrim-zijn. Abraham verwachtte de stad met fundamenten, waarvan God de ontwerper en bouwmeester is (Heb. 11:10). Die gezindheid laat zich lang niet altijd denken bij het gangbare spreken over cultuuropdracht, zoals wij dat kennen. Ook de afwijzing van Jezus als de tweede Adam in Mattheus 4 om in dienst van Satan alle koninkrijken der aarde aan zich ondergeschikt te maken, laat een ander licht vallen op de cultuuropdracht dan in de gangbaar opvatting: er uit halen wat er in zit. En is deze Jezus niet de Leidsman en Voleinder van het geloof (Heb. 12:2), die het kruis op zich nam en 
daarin de zin van de cultuur vervulde? En wat betekent dat kruisdragen voor christenen in de cultuur als navolgers van deze Leidsman en Voleinder van het geloof? Is dat niet het zoeken van de gerechtigheid van het Koninkrijk van God? En zou dat ook niet de juiste karakterisering van de cultuuropdracht zijn? Is niet elke cultuurarbeid daarom godsdienst?

Ook zouden we in verband met de gangbare interpretatie van de cultuuropdracht meer aandacht voor historische vragen moeten hebben. Bijvoorbeeld: waarom is de cultuuropdracht van Genesis, zoals die in onze tijd veelal wordt verstaan, door het joodse volk niet in de eerste plaats in een technische ontwikkeling vertaald? Leert de Bijbel ons niet dat het joodse volk juist van de techniek van de omringende volken, zelfs bij de bouw van de tempel, afhankelijk was? En moet het ons niet veel zeggen, dat meerderen - waaronder de eerder genoemde Ellul - er op gewezen hebben dat de Westerse - door de wetenschap gestempelde - technologie niet van joods-christelijke origine is, maar afkomstig van de Egyptische en Babylonische cultuur? Zijn Westerse christenen in het verstaan van de cultuuropdracht inderdaad vrij te pleiten van de (onmogelijk te christianiseren) ideeën van de Verlichting, die in de wetenschappelijk-technische beheersingsmacht bij uitstek de autonomie van de mens geconcentreerd zag?

Allemaal vragen die niet eenvoudig te beantwoorden zijn. Wel gaat er een suggestie van uit, die ik volledig voor mijn rekening zou willen nemen en die in het Nieuwe Testament ook bevestigd wordt als gesproken wordt over de positie van de navolgers van Christus in de wereld. Dan kan het niet anders dan opvallen dat het Nieuwe Testament, terwijl het deze aarde en onze werken daarop - ook die van de teclmiek - allerminst kleineert (Openb. 21:24; 1 Tim. 4:4,5), onze geestelijke aandacht richt op de gerechtigheid van het Koninkrijk van God dat in Clristus gekomen is en komende is. Dan dragen we ons kruis in de cultuur door het verzaken van de 'werken van het vlees': "Zoek de dingen die boven zijn" (Col. 3:1); "Waar uw schat is daar zal ook uw hart zijn" (Luk. 12:34); "Wat baat het een mens indien hij de hele wereld won ( - en dat is de inhoud van de ideologie van de technologie - E.S.), maar schade leed aan zijn ziel" (Marc. 8: 36); "Vergader II geen schatten op aarde ..." (Matt. 6:19); "Wordt niet gelijkvormig aan deze wereld." (Rom. 12:2); "Wij hebben hier geen blijvende stad, maar zoeken de toekomstige" (Heb. 13:14), enz. enz. (Schuurman, 1989:39 e.v.).

De verbinding van de goddelijke wereld met onze menselijke wereld door Christus - dus door genade - behoort onze cultuurhouding te stempelen. Dat is de houding van de liefde tot God en de liefde tot de naaste. Wij behoren ons in dc liefde tot God van onze geseculariseerde en door-en-door technologische cultuur te vervreemden on met die liefde ons vervolgens tot onze (ook verre) naaste en tot de cultuur te wenden: daarin ligt het eeuwigheidsperspectief in de cultuur En dat geeft ook de basis voor een verantwoord cultuur- en natuurbeheer. Tegenover aanbidding van de cultuur- en natuurgoden en in het verzet tegen het mate- 
Problemen en crisis van de opgezweepte Westerse technologische cultuur

rialisme, willen christenen ook in hun cultuur God gehoorzaam zijn. Techniek en economie worden bevrijd van vooruitgangs- en groeigeloof. Christenen zoeken temidden van de concentrerende en grootschalige technologische cultuur met haar macht, de divergerende en kleinschalige richting van de liefde, van de gerechtigheid, de dienstbaarheid, de offerbereidheid, de barmhartigheid en de dankbaarheid. Dat zijn kernwoorden die in het vocabulaire van de ideologie van de technologie - met alleen aandacht voor efficiëntie en effectiviteit - niet voorkomen. Ze impliceren een bekering van de ideologie van de technologie, van het technische volmaaktheidsideaal, het technische imperatief en het technisch imperialisme. Die bekering impliceert geen afstand doen van de technologie: we leven ervan, we kunnen niet zonder, maar ons hart zullen we er niet op mogen zetten, we leven er niet voor. Wel zijn we er dienstbaar mee.

\section{Perspectief voor de cultuur}

De hamvraag voor de breedte van de cultuur is: hoe kunnen we een opgezweepte technologische ontwikkeling in samenhang met een louter materialistische economie weer onder verantwoord beheer krijgen? Kan het proces van ontwrichting en verstoring van cultuur en natuur ook omgezet worden in een richting waarin - weliswaar vanwege ons leven 'tussen de tijden' - ten dele en voorlopige heelwording mogelijk is? Heroriëntatie is mogelijk, indien geleefd wordt uit het eeuwigheidsperspectief van het Koninkrijk van God. Dat geeft kracht en moed om de techniek haar betrekkelijke plaats - en daarmee haar zin - weer te laten innemen en de samenhang in de werkelijkheid en de zin en het wezen van de dingen weer te erkennen. Zoals eerder gezegd, techniek en economie worden dan bevrijd van vooruitgangs- en groeigeloof. Niet langer blijft de kwantitatieve benadering van de cultuurontwikkeling overheersend, maar de kwalitatieve krijgt aandacht.

Vanzelfsprekend zal het uitermate moeilijk zijn om de Europese cultuur van de weg van de opgezweepte technologie en de economische roes weer in rustiger vaarwater terug te brengen. Bijsturen, corrigeren, en afremmen van de hoofdtrend en alternatieven ontwikkelen is niet eenvoudig. In elk geval zou het wel zeer verstandig zijn, en ook nog tot de mogelijkheden behoren, om bij nieuwe ontwikkelingen niet in oude fouten te vervallen. Ik doel dan met name op de ontwikkeling van biotechnologie en genetische manipulatie. De verering van die techniek kan ertoe leiden dat deze technologie ons verraadt. Ecologische risico's worden onderschat als men denkt met biotechnologie 'schoon' te kunnen produceren. Voor genetische 'vervuiling' is dan geen oog; we zullen met een anders geaarde milieuvervuiling worden geconfronteerd.

Hoe kan voorkomen worden dat de technologie geen bedriegelijke of verwoestende invloed op de maatschappij heeft? En is er ruimte voor een (ten dele) heil- 
zame technische ontwikkeling? Echte techniek moet worden onderscheiden van geperverteerde, verraderlijke techniek. Het is vanwege de fouten van het verleden dat vanzelfsprekendheden onder verdenking behoren te staan. Onze problemen zien we vaak buiten het systeem van de wetenschappelijk-technische beheersing, terwijl daarmee de interne problematiek van de wetenschappelijk-technische beheersing zelf in de industrie, de landbouw, de gezondheidszorg, enz. over het hoofd wordt gezien. En daarin ligt nu juist - zoals in het voorgaande is aangetoond - de oorzaak van de grote problemen van onze tijd.

Ik zou dat nog eens extra willen toelichten aan de hand van de milieupolitiek. Terecht wordt daar veel aandacht aan gegeven. Algemeen leeft de gedachte dat nieuwe technologieën ons kunnen helpen. Dat is echter slechts ten dele waar, want wanneer technologische vernieuwing de milieuproblematiek ten dele terugdringt, zullen de intensiteit, de dynamiek en de schaalvergroting van de toepassing van die technologie de winst inzake de gezondmaking van het milieu weer teniet doen. We doen in de bestrijding van de milieuproblematiek met schone teclmologie dan wel een stap vooruit, maar omdat die stap plaats vindt binnen een voortgaande ontwikkeling van een materialistische economie, wordt die stap voorwaarts gevolgd door twee stappen achteruit. Dat doet zich voor bij een schoon producerende tuinbouw. De individuele tuinbouwer denkt met zijn 'schone produktie' een bijdrage aan de oplossing van het milieuprobleem te leveren. Maar een analyse van de kleine schaal naar de grote schaal leert dat het milieuprobleem verschoven wordt naar de energiebron.

Een ander voorbeeld: elektrische auto's zijn 'emissie-vrij', maar dat zijn de elektrische centrales, die deze auto's voeden, allenninst. In de meeste gevallen verbruiken deze gewoon fossiele brandstoffen, zoals aardgas of steenkool en soms zelfs aardolie. Bij kemcentrales doen zich weer andere milieudreigingen voor. Met de ontwikkeling van 'mestfabrieken' is iets soortgelijks aan de hand. De direkte problemen van de bio-industrie nemen er door af, zodat die industrie weer kan groeien, maar de reduktie van het dier tot een te manipuleren ding blijft ongemoeid

Deze bedreigende tendens in de bestaande technologische ontwikkeling blijft veelal verborgen, omdat economische en politieke machten ervan uitgaan dat de moderne, wetenschappelijke techniek boven elke kritiek verheven is. Haar ontwikkeling is immers voor de economische groei onontbeerlijk. Blijkbaar is milieupolitiek pas dàn effectief wanneer ook aandacht gegeven wordt aan extensiteit, afremıning van de dynamiek en voorkeur voor kleinschaligheid. Wanneer we daarvoor oog krijgen, zal ook het spreken over 'duurzame ontwikkeling' echt inhoud krijgen. Tot nu toe wordt door velen wel over 'duurzaamheid' gesproken, maar kan er niet echt inhoud aan gegeven worden. Zonder de trend van de cul- 
tuur te wijzigen, blijft het spreken over 'duurzaamheid' als een mythe funktioneren.

\section{Heroriëntatie}

Daarom terug naar de heroriëntatie: Het resultaat van het afremmen van de dynamiek in de cultuur en het stabiliseren ervan, zal zijn dat van veel onnodige en overbodige techniek afstand kan worden gedaan. Niet wat kan worden gemaakt, maar wat voor de mens nodig en gewenst is, moet in technische zin de aandacht krijgen. Techniek mag zich niet autonoom ontwikkelen, ze behoort als een prothese dienstbaar te zijn aan de mens. De technische macht en haar absoluutheidsaanspraken moeten worden beteugeld.

Verzet tegen de ideologie van de techniek en daarmee het doorbreken van het technische wereldbeeld betekent dan ook allerminst verzet tegen de technologie. Het gaat wel om een andere oriëntatie. Technologie kan dienstbaar zijn: dat geldt bijvoorbeeld voor de informatietechnologie. Deze technologie kan helpen het milieuprobleem terug te dringen. Want informatietechnologie is weinig ecologisch belastend, omdat de produktie en verspreiding ervan weinig energie en grondstoffen vergt, terwijl het vervuilingsaspect klein is, misschien zelfs wel te verwaarlozen. Informatietechnologie toepassen binnen een sterk gedecentraliseerde cultuur- en industrie-ontwikkeling zal minder schade toebrengen aan milieu en natuur.

En met een anders georiënteerde technische ontwikkeling zullen, om aan de geschetste dreigende dynamiek te ontkomen, ook andere processen van denken, handelen en andere maatschappelijke organisaties van de grond moeten komen. Bijvoorbeeld zal aan de concentratietendens - bijvoorbeeld in Nederland in de Randstad - naar grootschaligheid een eind moeten worden gemaakt. Want juist concentratie en grootschaligheid hebben de natuurverwoesting en milieuvervuiling inmiddels zelfs planetair gemaakt.

Een ander voorbeeld: in de technologische cultuur neemt het vervoer over de wegen enorm toe. Daaraan dragen zowel het personenvervoer als het goederenvervoer bij. Voor beide vormen nemen we dezelfde maatregelen: uitbreiding van het wegennet, met als gevolg een nieuwe aanslag op de natuur. Beter zou zijn het goederenvervoer ondergronds, - bijvoorbeeld onder de bestaande autowegen - , te doen plaats vinden. Een nieuwe aanslag op de natuur wordt vermeden, wel nemen de kosten van de techniek toe, maar een toename daarvan is een rem op het consumentisme en de dynamiek, dat ook in allerlei andere opzichten voordelen biedt. Over het algemeen krijgen we nu onze technologie te goedkoop, we houden geen rekening met de schade aan milieu en natuur. Verdisconteren we die schade wel of veel meer, dan wordt de techniek wel duurder, maar minder milieu- 
belastend. In zekere zin zijn we in onze materialistische maatschappij dus niet technisch genoeg. De verafgoding van de techniek leidt zelfs tot reduktie van de techniek!

Kortom, enerzijds zorgt de antropocentrische beheersingsdrift van de ideologie van de technologie - versterkt door een materialistische economie - voor veel onnodige en ongewenste technologie, anderzijds is die technologie geen uiting van echte creativiteit en wordt ze met minimale kosten gerealiseerd.

Oriëntatie op een andere techniek zal - zoals al gezegd - ook een andere oriëntatie in de economie tot gevolg moeten hebben - in die volgorde! Een herbezinning op een nieuwe economische orde, zonder aandacht voor de 'ideologie van de technologie' is gedoemd te mislukken. Op economisch vlak moet gezocht worden naar een nieuw macro-economisch systeem waarbij de waarde van een goed een functie moet zijn van zijn 'ecologische relevantie', dat wil zeggen dat rekening wordt gehouden met de impact die produktie en consumptie ervan heeft op energie, grondstoffen, pollutie en aantasting van eco-systemen. Tegenover een 'tunnel-economie' als een materialistische economie, zouden we liever het beeld van een 'boom-economie' willen gebruiken - het beeld is van Goudzwaard. Dat beeld voldoet aan de ecologische voorwaarden, laat ruimte voor groei, maar de resultaten of - beter - de vrucliten, zijn meer proportioneel.

Het valt buiten het bestek van dit artikel om nog meer op de mogelijkheden van een meerzijdige, creatieve en rijkgevarieerde orde of structuur van de techniek uitvoerig in te gaan. In aansluiting bij de bekende Schumacher (1973 en 1977), zou ik een samenvatting willen geven: Vanuit het motief van de liefde tot God, liefde tot de naaste en liefde tot Gods schepping - en dus met alle aandacht voor de menselijke verantwoordelijkheid - moeten voor de techniek ethische toetsingskaders worden ontwikkeld. De grond voor deze toetsingskaders is gelegen in de gerechtigheid als de samenhang van de scheppings- en verlossingsorde. Die orde is Godsorde. Een cultuur die zich daaraan oriënteert is niet langer anthropocentrisch maar theocentrisch. De uitwerking van die Godsorde laat een grote verscheidenheid aan normen zien (Schuurman, 1990:100 e.v.). En deze ethische kaders als normatieve kaders moeten de informatietechnologie, de biotechnologie, de genetische manipulatie, enz., aan banden leggen. Vervolgens zullen in de sectoren waarin de verantwoorde techniek gebruikt wordt, zoals industrie, landbouw, onderwijs, gezondheidszorg, enz., wel niet alle problemen worden opgelost, maar ze zullen bimnen de perken worden gehouden en niet ondraaglijk worden, zoals momenteel door de overschatting van de wetenschappelijk-technische beheersing gebeurt. De cultuurontwikkeling zal er meer stabiel en duurzaam door worden! De schepping en de (vooral verre) naaste zullen er wel bij varen, terwijl de zin van de techniek (ten dele) gerealiseerd kan worden (Schuunnan, 1989:64 e.v.). 


\section{Bibliografie}

CORBEY, R. \& VAN DER GRIJP, P. reds. 1990. Natuur en cultuur. Baarn : Ambo DOOYEWEERD, H. 1949. Reformatie en Scholastiek in de Wijsbegeerte. Franeker : Wever. ELLUL, J. 1980. The Technological System. Continuum : New York

IHDE, D. 1985. The Historical-Ontological Priority of Technology over Science. (In Hickman, L. Philosophy, Technology and Human Affairs. IBIS : Texas. p. 196-211.)

KUYPER, A. 1911. Pro Rege. Deel I. Kampen : Kok

MEADOWS, D.L. e.a. 1992. De grenzen voorbij - en wereldwijde catastrofe of een duurzame wereld. Baarn : AULA

SCHUMACHER, E.F. 1973. Hou het klein. Baarn : Ambo

SCHUMACHER, E.F. 1977. Gids voor verdoolden. Baarn : Ambo.

SCHUURMAN, E. 1985. Tussen technische overmacht en menselijke onmacht. Kampen Kok

SCHUURMAN, E. 1989. Het technische paradijs. Kampen : Kok

SCHUURMAN, E. 1990. Filosofie van de Technische Wetenschappen. Leiden : Martinus Nijhoff.

STRIJBOS, S. 1988. Het technische wereldbeeld. Amsterdam : Buyten en Schipperheyn

TILLICH, P. 1986. The Spiritual Situation in Our Technical Society. New York: Scribner 